\title{
Experimental Study on Mechanical Properties of Prefabricated Single-Cracked Red Sandstone under Uniaxial Compression
}

\author{
Yue Yuan $\mathbb{D}^{1},{ }^{1}$ Jinlei Fu, ${ }^{2}$ Xiaolei Wang $\mathbb{D},{ }^{3}$ and Xi Shang ${ }^{4}$ \\ ${ }^{1}$ Work Safety Key Lab on Prevention and Control of Gas and Roof Disasters for Southern Coal Mines, \\ Hunan University of Science and Technology, No. 2 Taoyuan Road, Yuhu District, Xiangtan 411201, China \\ ${ }^{2}$ Guizhou Research Institute of Coal Mine Design Co., Ltd., No. 48, Dazhi Road, Xibei Street, Huaxi District, \\ Guiyang 550025, China \\ ${ }^{3}$ School of Civil Engineering, Hebei University of Engineering, No. 19, Taiji Road, Economic Development District, \\ Handan 056038, China \\ ${ }^{4}$ School of Resource, Environment and Safety Engineering, Hunan University of Science and Technology, \\ No. 2 Taoyuan Road, Yuhu District, Xiangtan 411201, China
}

Correspondence should be addressed to Xiaolei Wang; wangsanshi2003@163.com

Received 14 August 2020; Revised 3 November 2020; Accepted 11 November 2020; Published 29 November 2020

Academic Editor: Fengqiang Gong

Copyright (c) 2020 Yue Yuan et al. This is an open access article distributed under the Creative Commons Attribution License, which permits unrestricted use, distribution, and reproduction in any medium, provided the original work is properly cited.

\begin{abstract}
This paper aims at the phenomenon of the fractured rock column in underground engineering which is prone to collapse when subjected to ground pressure. Uniaxial compression test and particle flow code (PFC2D) are used to analyze the influence of crack dip angle on the mechanical properties, crack propagation, and the failure mode of red sandstone. From the results, it is observed that the stress-strain curve of the precracked red sandstone can be divided into five stages, and there is a critical stress value in the stage of accelerated crack propagation and unstable fracture of the rock sample. Further, the peak strength, maximum strain, and the elastic modulus of the precracked red sandstone increase with the increase of crack dip angle, and the ultimate failure mode of rock sample changes from the "ladder" type failure to slope uneven failure. Furthermore, from PFC2D simulation, it is found that the tensile microcracks contribute more towards the failure of rock samples than the shear cracks. The contact force chain is very weak at the places where the precracks and macroshear planes are formed. This indicates that the original contact force is weakened due to particle fracture. Therefore, the bearing capacity of the precracked rock samples decreases with the increase in load. From the simulation results, it is found that the displacement at the shear plane of the rock sample is large, and the shear dilatation occurs. With the increase in load, the specimen falls off and is ejected. This is due to the weakening of the contact force between the internal particles. Thereafter, it fractures to produce microcracks, which gradually converge, thus providing a prerequisite for the transformation of elastic strain energy into kinetic energy.
\end{abstract}

\section{Introduction}

The underground pillars are under uniaxial compression. In general, the underground rock column has fracture development and some initial damage. Further damage occurs under loading. When the underground pillars are affected by dynamic loads such as blasting and rock burst, instability occurs. This leads to a mine disaster. The stability of the rock column is related to the stability and safety of the whole underground structure [1]. It is often difficult to make closed cracks in laboratories and closed cracks in practical engineering are also rare. Therefore, it is of general significance to study the problem of precast nonclosed cracks in rock samples that are under loading [2-5]. It is difficult to effectively monitor the microcracks in laboratory rock samples. The discrete element particle flow code (PFC) can be used to simulate the propagation of microcracks. It can simulate the problems from point to surface, step by step to final failure. It is more suitable for explaining the damage and failure evolution process of rock [6-8].

Some scientific research has been carried out on precracked rocks. Cao et al. observed three types of coalescence 
patterns in between the intermittent fractures [9]. Yang et al. studied the fracture characteristics of brittle sandstone with two noncoplanar fractures by using experiments and numerical simulation [10]. Huang et al. summarized the tensile failure mode and three-dimensional damage evolution characteristics of sandstone through acoustic emission signal [11]. Chen et al. studied the mechanical parameters and the failure characteristics of $\mathrm{T}$-shaped cross fractures [12].

The geometric parameters and the filling properties of preexisting flaws have an important influence on the mechanical properties, crack propagation, and the deformation failure mode of rock. Extensive studies were conducted under uniaxial loading in order to investigate the damage evolution of a rock or rock-like materials containing prefabricated crack. Wong et al. studied the crack propagation mechanism, crack initiation angle, and the failure mode of the precracked specimens using the uniaxial compression test [13-16]. Further, crack initiation and propagation for samples with a single nonstraight fissure were investigated $[17,18]$. Zhang [19] simulated the cracking process in a rocklike material containing a single flaw using a numerical approach based on the particle element model. Lin et al. derived the relationship between the crack initiation angle of the open flaw tip and the dip angle of the prefabricated flaw under compression conditions [20]. Niu identified the change from microcracking to macrocracking using the acoustic emission system in the uniaxial compression tests $[21,22]$. Zhao et al. analyzed the influence of the flaw dip angle and the filling material on the crack initiation stress and the peak strength $[23,24]$. Moreover, the full-field strain evolution, fracture mode and the acoustic emission (AE) fractal characteristics of samples with a single preexisting flaw were comprehensively studied [25-27].

From the literature, it is observed that the crack initiation, propagation, and mechanical properties of precracked rocks were extensively investigated. However, limited studies were conducted on the failure mode, damage effect, and the fracture characteristic stress of soft rocks with a single flaw using experiments and the mesoscopic simulation. Therefore, in this work, the red sandstone with a prefabricated single crack is considered for the study, and the uniaxial compression experiment is carried out. Simulation is carried out using PFC2D in order to explore its mechanical properties and study the crack propagation law from the macro- and microview. It is also studied to summarize the failure mode of instability in order to reveal the failure characteristics of precracked sandstone. Moreover, it has important reference significance for the evaluation of the stability of the underground rock column.

\section{Experimental Details of the Uniaxial Compression Experiment on Dip Angle Effect of the Single-Cracked Red Sandstone}

The materials, experimental details, and the experimental plan of the uniaxial compression experiment are briefly described below.
2.1. Experimental Materials. The material that is used for the experiments is red sandstone. For conducting the experiment, red sandstone with high homogeneity, a few natural joints, and good integrity is selected. The physical and mechanical properties of the rock are shown in Table 1. The "Rock Experiment Specification for Water Conservancy and Hydropower Engineering" (sl264-2001) is taken as the standard of experimental processing [28]. The red sandstone is processed according to the standard into a cylinder with dimensions $\varphi 50 \mathrm{~mm} \times 100 \mathrm{~mm}$. Further, the specimen is flattened on both ends and controlled within $\pm 0.05 \mathrm{~mm}$. The precast cracked red sandstone specimen is shown in Figure 1.

2.2. Experimental Details. In this work, RYL-600 which is a shear rheological tester developed by the Provincial Key Laboratory of Safe Mining Technology of Coal Mine, Hunan University of Science and Technology, is used (Figure 2). The uniaxial compression tests of the precracked red sandstone under different dip angles are carried out. The instrument is used for conducting strength tests, relaxation tests, triaxial rheological tests, and shear rheological tests, with the characteristics of high stiffness, high control precision, and good stability. The technical parameters considered for curing the experiment is as follows. The maximum axial test force and the maximum load are taken as $600 \mathrm{kN}$ and the error of deformation measurement is considered to be $\leq \pm$ $0.5 \%$. The axial control modes that are used for conducting the experiment are displacement control mode and experimental force control mode. Further, the control accuracy is considered as $\pm 0.1 \%$ and $\pm 0.2 \%$ for displacement error and experimental force measurement error, respectively.

2.3. Experimental Plan. Initially, the red sandstone is prefabricated into an unclosed single-crack rock sample with crack dip angles $\alpha$ of $0^{\circ}, 15^{\circ}, 30^{\circ}, 45^{\circ}, 60^{\circ}, 75^{\circ}$, and $90^{\circ}$, respectively. Further, the crack is located at the center of the specimen. The length and width of the prefabricated crack are $15 \mathrm{~mm}$ and $1 \mathrm{~mm}$, respectively. According to the crack angle, the rock is divided into seven groups, three rock samples in each group which total up to twenty-one rock samples. The axial loading system of the RYL-600 shear rheometer is used in the experiment, and the loading speed is controlled at $100 \mathrm{~N} / \mathrm{s}$. The plan of the uniaxial compression test for the precracked red sandstone is shown in Table 2. According to the loading rate $(0.5 \mathrm{MPa} / \mathrm{s})$ which is recommended by the International Society of Rock Mechanics, and considering the need for an experimental observation in the cracking process, the set loading rate must be lower than $0.5 \mathrm{MPa} / \mathrm{s}$. Therefore, the loading rate is set as $100 \mathrm{~N} / \mathrm{s}$ in this experiment.

\section{Analysis of the Experimental Results}

The analysis of the experimental results such as the stress-strain curves, deformation parameters, and the failure modes are discussed in detail below. 
TABLE 1: The physical and mechanical parameters of the rock specimens.

\begin{tabular}{|c|c|c|c|c|c|}
\hline Lithology & $\begin{array}{l}\text { Uniaxial compressive strength (UCS) } \\
(\mathrm{MPa})\end{array}$ & $\begin{array}{l}\text { Tensile strength } \sigma_{\mathrm{t}} \\
(\mathrm{MPa})\end{array}$ & $\begin{array}{l}\text { Elastic modulus } E \\
(\mathrm{GPa})\end{array}$ & $\begin{array}{c}\text { Poisson's ratio } \\
\mu\end{array}$ & $\begin{array}{l}\text { Density } \rho \\
\left(\mathrm{kg} \cdot \mathrm{m}^{-3}\right)\end{array}$ \\
\hline $\begin{array}{l}\text { Red } \\
\text { sandstone }\end{array}$ & 80.43 & 4.75 & 5.02 & 0.20 & 2403.33 \\
\hline
\end{tabular}

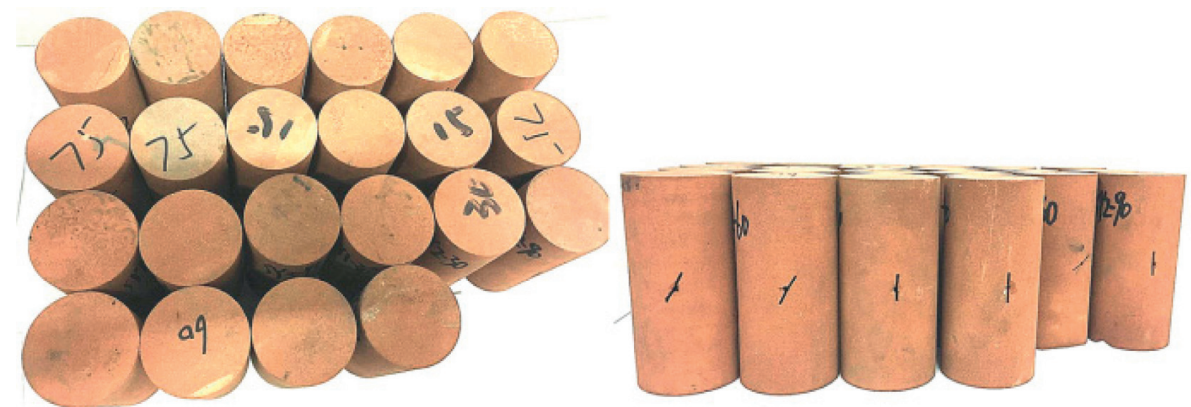

Figure 1: Prefabricated single-crack red sandstone specimens.

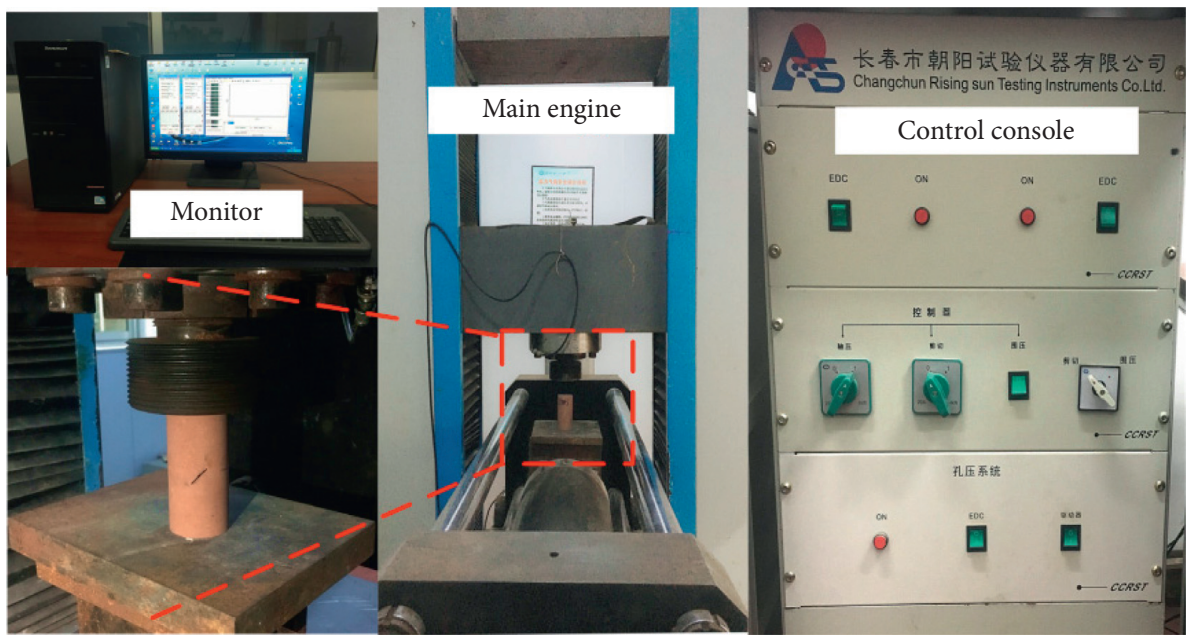

Figure 2: Photographs of the shear rheometer.

TABLE 2: Plan for the uniaxial compression experiment for the red sandstone specimens.

\begin{tabular}{|c|c|c|c|c|c|c|c|}
\hline Group & Crack arrangement & Specimen number & Loading rate $v\left(\mathrm{~N} . \mathrm{s}^{-1}\right)$ & $\begin{array}{c}\text { Crack length } \\
2 \mathrm{a}(\mathrm{mm})\end{array}$ & $\begin{array}{l}\text { Crack width } \\
2 \mathrm{~b}(\mathrm{~mm})\end{array}$ & Crack dip angle $\alpha\left(^{\circ}\right)$ & $\begin{array}{c}\text { Number of } \\
\text { specimens }\end{array}$ \\
\hline A & & SY0-1 3 & & & & 0 & \\
\hline B & & SY15-1 3 & & & & 15 & \\
\hline $\mathrm{C}$ & $\Xi$ & SY30-1 3 & & & & 30 & \\
\hline $\mathrm{D}$ & 。ำ & SY45-1 3 & 100 & 15 & 1 & 45 & 3 \\
\hline $\mathrm{E}$ & & SY60-1 3 & & & & 60 & \\
\hline $\mathrm{F}$ & & SY75-1 3 & & & & 75 & \\
\hline G & $50 \mathrm{~mm}$ & SY90-1 3 & & & & 90 & \\
\hline
\end{tabular}




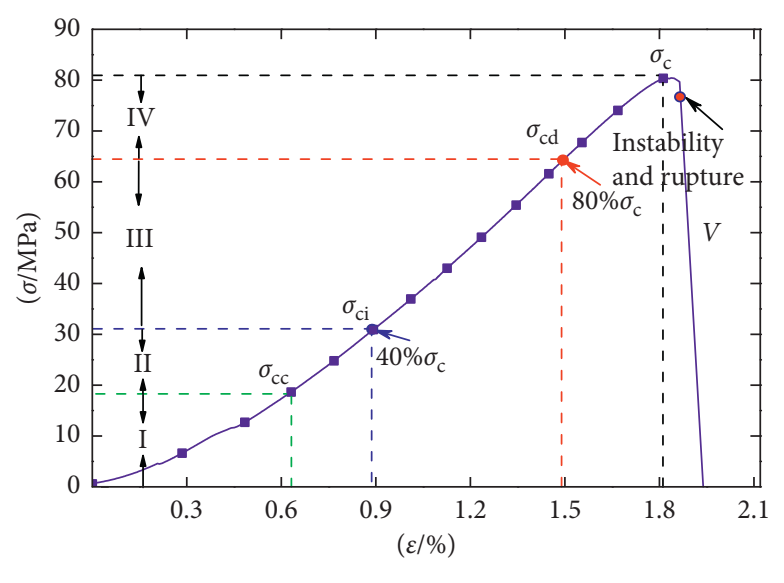

- Intact specimen

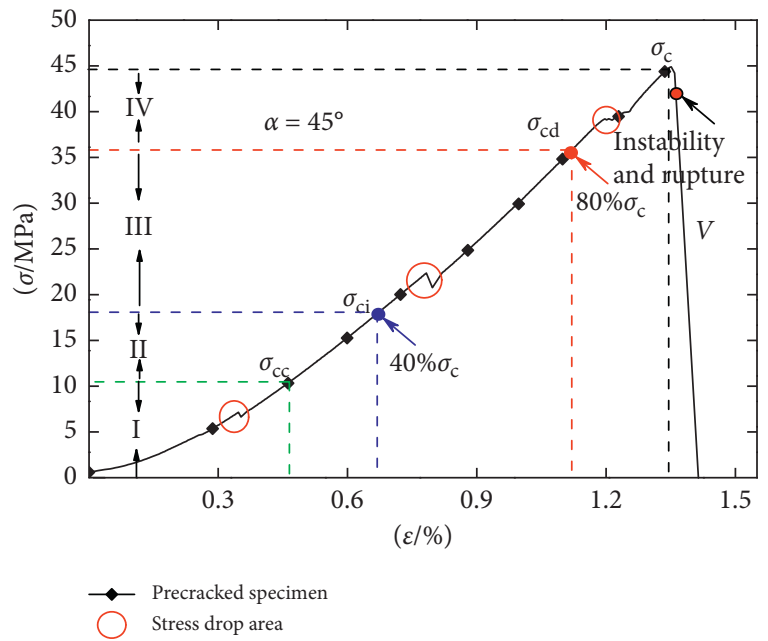

(b)

FIgURE 3: Stress-strain curves for red sandstone specimens: (a) without prefabricated crack and (b) with a single prefabricated crack.

3.1. Stress-Strain Curve. The stress-strain curve reflects the progressive process of the internal pore compaction, microcrack closure, new crack initiation, propagation, coalescence, and the instability of the failure. The stress-strain curves of intact red sandstone and single precracked red sandstone $\left(\alpha=45^{\circ}\right)$ under uniaxial compression loading are shown in Figure 3. According to the loading characteristics of the experimental curve, the stress-strain $(\sigma-\varepsilon)$ curve of red sandstone is divided into five stages for analysis [29-31]. The first stage is the microfracture and pore compaction stage. During the initial stage of axial stress loading, the original open structural planes or the microcracks close gradually. The pore volume decreases with increasing axial force, and the rock sample is compacted in order to form nonlinear deformation at the early stage. The $\sigma-\varepsilon$ curve is approximately a "concave" nonlinear segment, and the axial force at the end of this stage is the closure stress $\sigma_{\mathrm{cc}}$ of the rock sample $[32,33]$. The second stage is the elastic deformation stage. During this stage, the $\sigma-\varepsilon$ curve is approximately inclined "straight line." The pore volume strain tends to be stable and the axial force at the end of this stage is the crack initiation stress $\sigma_{\mathrm{ci}}$. The third stage is crack initiation and stable growth stage. In this stage, with the increase in axial force, the microcracks further crack to form new cracks, and the cracks continue to expand at a stable speed. Further, the loading time is longer, and the axial force at the end is the damage strength of rock sample $\sigma_{\mathrm{cd}}$. $[32,33]$ The fourth stage is accelerated crack propagation and unstable fracture of the rock sample. During this stage, the turning point of the rock sample changes from elastic to plastic, and the yield point is generated. Further, the cracks accelerate to form a certain cross fracture surface, and the rock sample surface is accompanied by an unstable fracture. When the bearing capacity of the rock sample reaches the peak strength, the internal structure of the rock sample is dislocated. Further, it is accompanied by a weak cracking sound with a short duration. The phenomenon of sliding off the macroshear plane does not occur, and the overall shape of the rock sample is maintained. The axial force at the end of this stage is the peak strength $\sigma_{c}$. The final stage is the postpeak fracture instability stage. During this stage, the bearing capacity of the rock sample decreases slightly with the increase in deformation. Further, the intersecting fracture surfaces become macroscopic fracture surfaces. Thereafter, the bearing capacity of the rock sample is suddenly lost with a sudden loud noise. The axial stress drops to zero instantaneously, and finally, the rock sample becomes unstable. This phase takes place in a very short duration of time.

In Figure 3, the results of the precracked sample are compared with the results of the intact sandstone sample. It is observed that the prefabricated crack causes initial damage to the rock sample, resulting in a lower $\sigma_{\mathrm{c}}$ value and shorter duration of each stage. The obvious stress drop before the peak value may be due to the initiation and expansion of microcracks in the rock sample. The macrofracture on the surface of the rock sample and the slip and dislocation of the rock structure may lead to the decrease of the rock bearing capacity and the drop of the axial stress of the rock sample.

3.2. The Strength and the Deformation Parameters. Figure 4 shows the $\sigma-\varepsilon$ curves of precracked red sandstone samples and intact rock samples under uniaxial compression. Figure 5 shows the comparison of the peak strength changes and marks the instability fracture point in the figure. The color from blue to red indicates the value of $\sigma_{\mathrm{c}}$. From Figures 4 and 5, it is observed that the peak strength $\sigma_{\mathrm{c}}$ increases, and the strain $\varepsilon$ increases with the increase in crack dip angle $\alpha$. Further, from Figure 5, it is observed that when the rock sample reaches $\sigma_{\mathrm{c}}$, the color changes from red to blue instantly. This indicates that the axial stress decreases rapidly, and finally the rock sample develops instability fracture. The instability fracture occurs after the decrease of $\sigma_{\mathrm{c}}$. Therefore, $\sigma_{\mathrm{c}}$ can be taken as the critical stress value for instability failure. The peak strength and elastic modulus increase with the increase in the crack dip angle. 


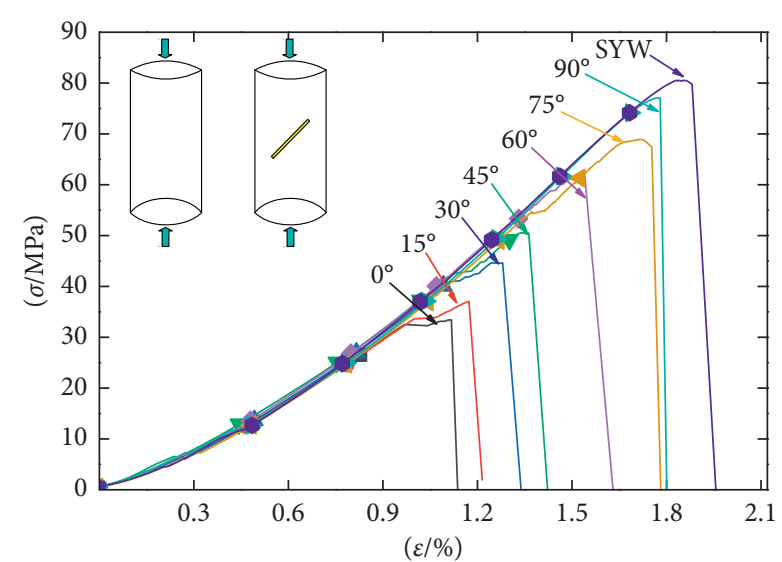

FIgURE 4: Stress-strain curves of the red sandstone specimens under different crack dip angles.

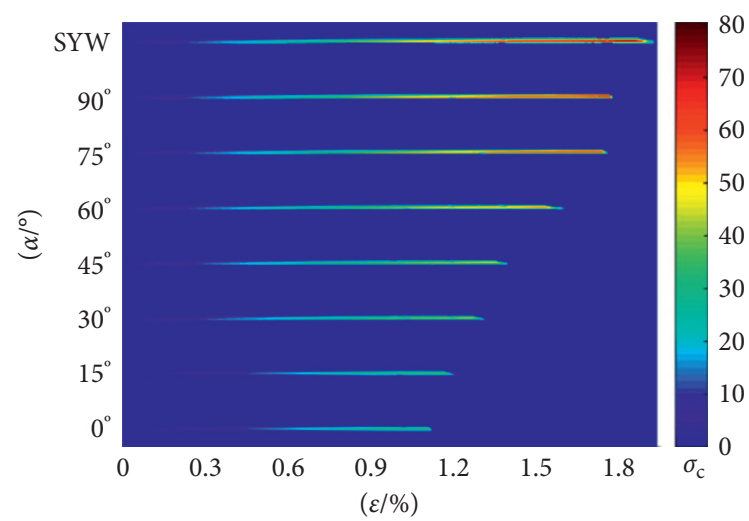

Figure 5: Peak strengths of the red sandstone specimens under different crack dip angles.

By combining the obtained experimental data, it is found that the relationship between the peak strength and the crack dip angle is fitted linearly (Figure 6(a)). Moreover, it is observed that the peak strength and the elastic modulus increase as the crack dip angle increases. Among them, the elastic modulus increases nonlinearly as the crack dip angle increases (Figure 6(b)).

Figure 7 shows the relationship between the maximum strain, peak strength, elastic modulus, and the crack dip angle. The results show that the maximum strain (i.e., the ultimate strain of the rock specimen after failure and the instability) increases step by step as the crack dip angle increases, and thus it further increases the amplitude in the later stages. Further, the variation of the peak strength and the elastic modulus with the crack dip angle is found to be similar. Moreover, the peak strength and the elastic modulus increase slowly in the early stage but increase sharply after the crack dip angle exceeds $45^{\circ}$. Further, it is observed that they continue to increase almost linearly until the maximum value at the intact rock sample. Furthermore, from Figures 5-7, it is observed that the peak strength of the red sandstone specimens with various crack dip angles decreases to varying degrees when compared with the intact specimens. Therefore, in order to characterize the damage effect of the prefabricated crack with different dip angles on the rock specimens, the damage coefficient $K_{\mathrm{d}}$ is defined as shown in the following equation [34]:

$$
K_{d}=\frac{\sigma_{\mathrm{cw}}-\sigma_{c}}{\sigma_{\mathrm{cw}}} .
$$

In the previous equation, $\sigma_{\mathrm{cw}}$ refers to the peak strength of the intact rock specimen and $\sigma_{\mathrm{c}}$ refers to the peak strength of the rock specimen with a single preexisting crack.

From Figure 8, it is observed that the average damage coefficient of the rock samples is 0.533 when the crack dip angle is $0^{\circ}$, and the average damage coefficient of the rock samples is found to be 0.056 when the crack dip angle is $90^{\circ}$. Further, the damage coefficient of the red sandstone specimen with a single prefabricated crack generally shows a nonlinear decreasing trend with the increase of the crack dip angle, and the reduction gradually becomes flat. Thus, the damage coefficient $K_{\mathrm{d}}$ can reflect the damage effect of the crack dip angle on the peak strength of the rock sample in a better way.

3.3. Failure Mode of Red Sandstone. The uniaxial compression tests of precracked sandstone and intact sandstone are carried out by using a shear rheometer. The final failure mode is shown in Figure 9. The results show that the prefabricated cracks of the rock sample are through fractures, and the failure modes of both sides of sandstone are similar. Therefore, only one side is selected to analyze the influence of the crack dip angle $\alpha$ on the failure mode. Tensile crack (T) and shear crack $(S)$ is produced in rock sample under loading, and the angle between shear crack and prefabricated crack is $\beta$.

When the dip angle of the prefabricated crack is $\alpha=0^{\circ}$, the inclined shear cracks are formed at both the ends of the prefabricated cracks which are accompanied by macrotensile cracks. The airfoil crack forms between the shear crack and the prefabricated crack and finally penetrates through the rock sample to form a stepped failure. When the dip angle of the prefabricated crack is $\alpha=15^{\circ}$, a shear crack inclined to the upper left is formed at the left end of the prefabricated crack. A shear crack inclined to the right and down is formed at the right end of the prefabricated crack which is accompanied by a macrotensile crack. With the action of load, some fragments are formed, and finally, the rock sample is destroyed during the antistep failure. When the dip angle of the prefabricated crack is $\alpha=30^{\circ}$, the fracture mode of the rock sample is similar to that of $\alpha=0^{\circ}$. The angle $\beta$ between the shear crack and the prefabricated crack at both the ends of the prefabricated crack increases and the increased angle is approximately equal to $\alpha$.

When the dip angle of the prefabricated crack is $\alpha=45^{\circ}$, under loading condition, the rock sample forms a small angle between the shear crack and the airfoil crack at both the ends and thereafter exhibits the fragment peeling phenomenon. The final shear mode crack penetrates through the specimen and causes failure. When the dip angle of the prefabricated crack is $\alpha=60^{\circ}$, with the increase in the dip 


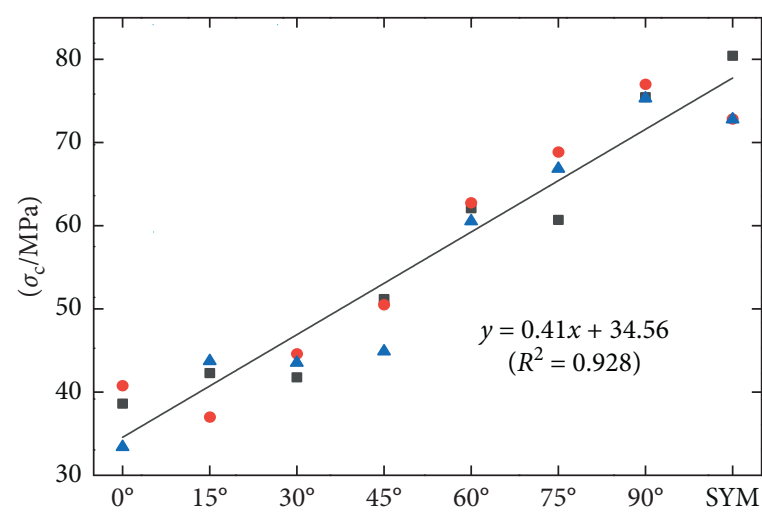

$(\alpha)$

- SY-1

- SY-3
- SY-2

— Fitting curve

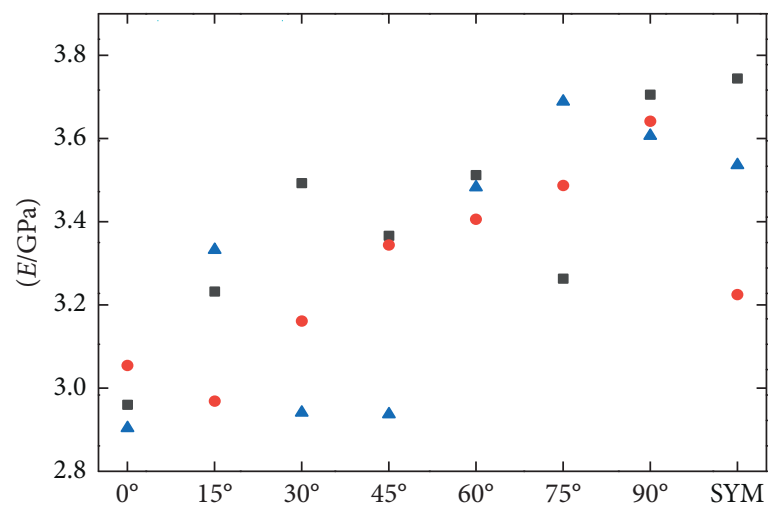

$(\alpha)$

- SY-1

- SY-3

- SY-2

(a)

(b)

FIGURE 6: Variation of the peak strength and the elastic modulus for the red sandstone specimens with the crack dip angle: (a) peak strength and (b) elastic modulus.

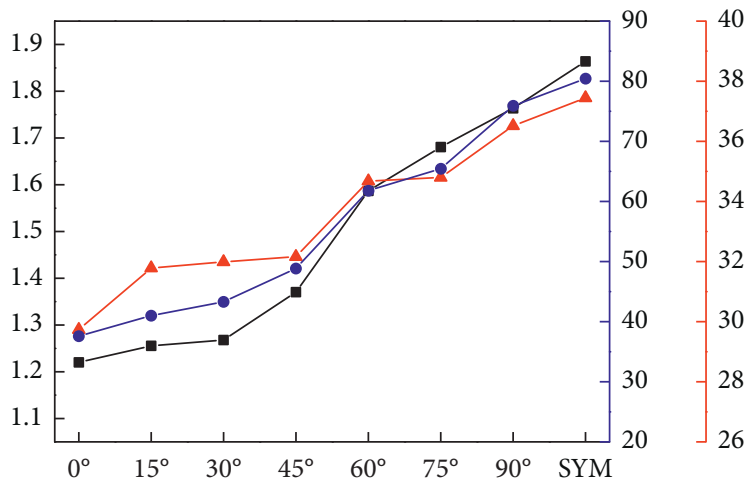

$(\alpha)$

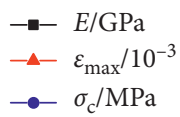

Figure 7: Relationship curves of the peak strength, elastic modulus, maximum strain, and the crack dip angle.

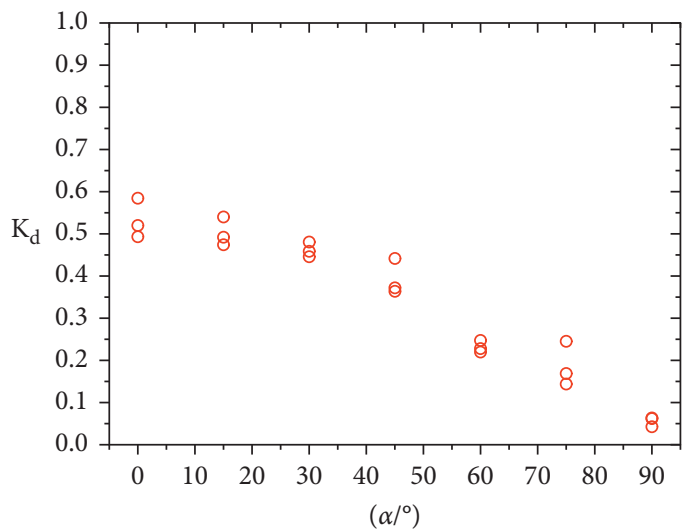

FIgURE 8: Damage coefficients of the red sandstone specimens under different crack dip angles. 


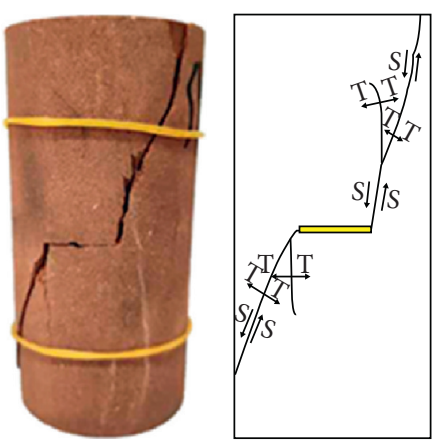

$\alpha=0^{\circ}$

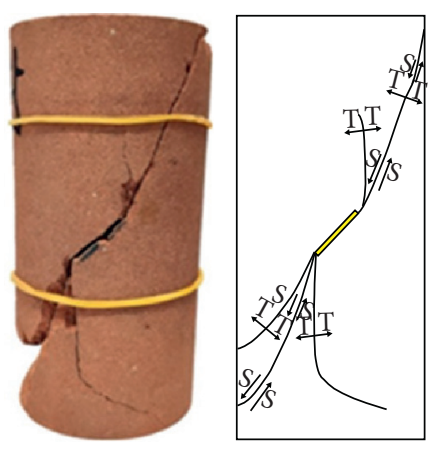

$\alpha=45^{\circ}$

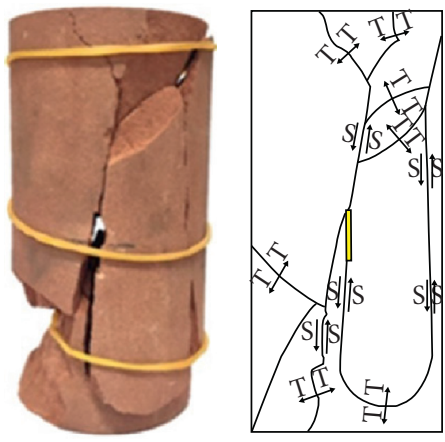

$\alpha=90^{\circ}$

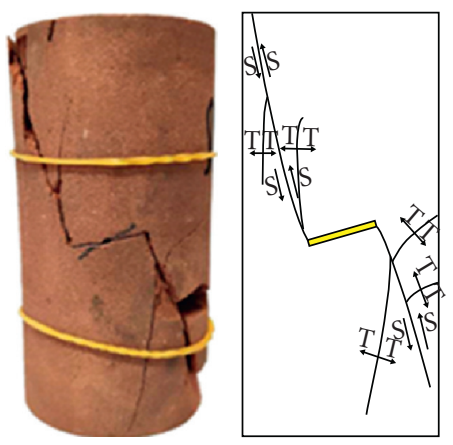

$\alpha=15^{\circ}$
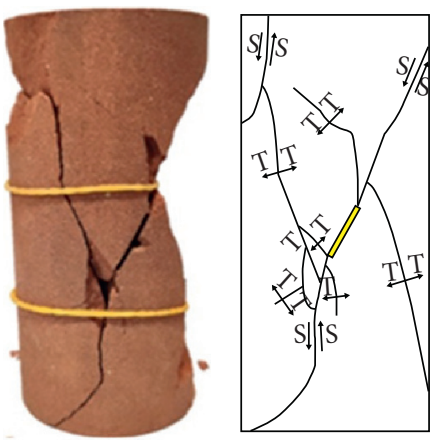

$\alpha=60^{\circ}$

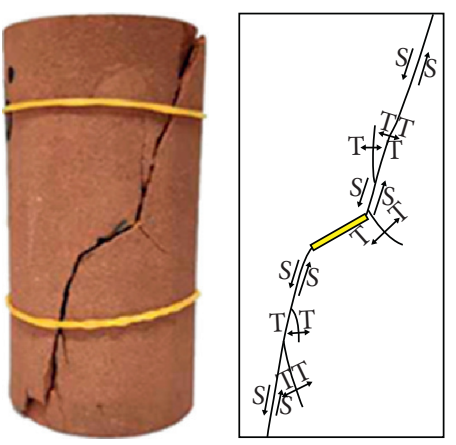

$\alpha=30^{\circ}$

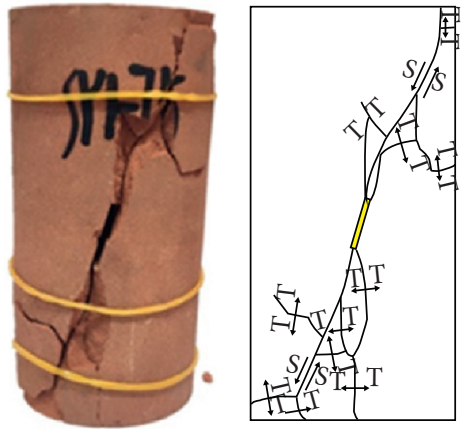

$\alpha=75^{\circ}$

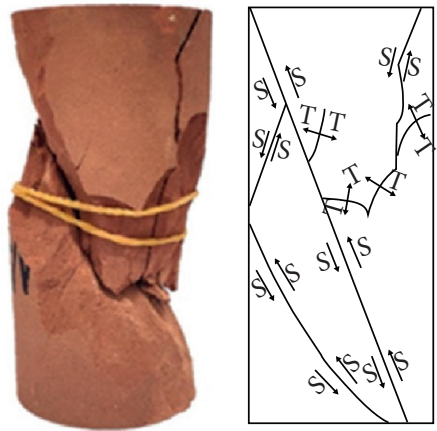

Without prefabricated crack

FIGURE 9: Failure modes of the red sandstone specimens with different crack dip angles. S stands for shear crack and T stands for tensile crack.

angle, the peak strength of the rock sample increases gradually, and its bearing capacity is stronger. Under the combined action of composite stress, the ultimate failure mode of the rock sample is two cones with one block on each side.

When the dip angle of the prefabricated crack is $\alpha=75^{\circ}$, the inclined shear cracks are formed at both the ends of the prefabricated crack, which are approximately coplanar with the prefabricated crack. Finally, the rock sample is destroyed in the form of oblique shear, and the volume expansion of the rock sample is large. When the dip angle of the prefabricated crack is $\alpha=90^{\circ}$, the rock samples show uneven failure. Small fragment peeling and block shedding exist simultaneously. The peak strength is close to the intact rock sample, and the accumulated energy is stronger than the other precracked sandstone. Therefore, the energy release will lead to more serious damage and uneven failure. The damage of intact sandstone is more serious than that of the precracked sandstone. Debris, small fragments, and blocks are more serious than the precracked sandstone. Although the peak strength is slightly higher, the accumulated energy is much higher than that of the precracked sandstone, and the uneven failure along the shear plane is more serious.

With the increase in the dip angle $\alpha$ of the prefabricated crack, the crack and the prefabricated crack is subjected to combined stress. The secondary cracks around the prefabricated cracks initiate and gradually expand to both the ends of the specimen, which eventually leads to failure. The prefabricated crack will change the failure mode of the sandstone, crack initiation, and propagation to ultimate instability under uniaxial compression. When $0^{\circ} \leq \alpha \leq 60^{\circ}$, the crack propagation path is regular, the dip angle $\alpha$ of the prefabricated crack increases approximately with the angle $\beta$ between the shear crack and the prefabricated crack, and $\alpha \approx \beta$. When $\alpha>60^{\circ}$, heterogeneous failure of rock sample 
occurs. The failure mode of the precracked sandstone under uniaxial compression is as follows: when $0^{\circ} \leq \alpha \leq 30^{\circ}$, the shear failure of the precracked sandstone transits to tension shear composite failure; when $45^{\circ} \leq \alpha \leq 60^{\circ}$, there is a transition from tensile shear composite failure to tensile failure of precracked sandstone; and when $75^{\circ} \leq \alpha \leq 90^{\circ}$, the tensile failure of precracked sandstone is transitional to heterogeneous failure.

\section{Numerical Experiment Using PFC}

The details of the numerical experiment conducted using PFC is discussed below.

4.1. Basic Theory of PFC. When particle flow code PFC is used for simulation, the particle shape and contact state should be correspondingly assumed. The basic assumptions of PFC include the following. The basic particle element of the numerical model is assumed to be a disk or a sphere, and the particle element is considered as a rigid body. In a very small space area, the particle elements are assumed to be almost in the form of point contact, and the contact parts are assumed to have certain bonding characteristics. Further, it is assumed that there is a certain amount of overlap at the contact between the particle elements, and the relationship between the particle element and the contact force is established by the force-displacement theory [35-37].

In the numerical calculation process of PFC, Newton's second law and force-displacement law are the basic theories, in which the force-displacement law constitutes the physical equation and Newton's second law constitutes the motion equation [35]. Ten contact models are provided in PFC5.0. In this work, the parallel bonding model in PFC is mainly used, and the schematic diagram of the parallel bonding model is shown in Figure 10.

4.2. Construction of the Numerical Model. The discrete element model of red sandstone with a single precrack is established by the following method. The rock particles in the model are simulated by using a single sphere. PFC simulation of uniaxial compression includes the following four steps. In the first step, the numerical experiment container is generated, and in the second step, the parallel bonding parameters are set. During the third step, the model of a single crack is established by using AutoCAD, and the contour of a single crack is generated by importing into the PFC program. Further, by deleting the particles in the crack contour, an unclosed crack is formed. Finally, in the last step, the upper and lower walls are controlled in order to perform uniaxial loading with a loading speed of $0.1 \mathrm{~mm} / \mathrm{s}$.

According to the abovementioned establishment of a discrete element uniaxial compression experiment, the parameters of the red sandstone uniaxial test are calibrated. The parallel bonding model is used to simulate and the mesocontact model parameters of the red sandstone are obtained (Table 3).

Figure 11 shows the comparison results of the uniaxial tests and numerical experiments for red sandstone. From Figure 11(a), it is observed that the stress-strain curves obtained by numerical experiments are in good agreement with the laboratory experiments. From Figure 11(b), it is observed that the shear plane formed by the failure of the numerical test specimen is consistent with the uniaxial test results.

4.3. Failure Evolution of Red Sandstone with a Single Prefabricated Crack. Using the calibrated mesoparameters, the uniaxial compression experiments of the single precracked sandstone under different dip angles are simulated (Figure 12). Figure 12 shows the experimental failure diagram, PFC simulation failure diagram (red for tensile crack and black for shear crack), contact force chain diagram, and the displacement field diagram. From Figure 12, it is observed that, during the PFC simulation, microcracks initially appear in the sample. Further, with the increase in load, the microcracks converge together, and cracks and shear planes appear in the macroscopic view. However, the red tensile cracks are more in the final failure of rock samples, which indirectly indicates that tensile microcracks contribute more towards the failure of the rock samples than the shear cracks. With the increase in crack dip angle $\alpha$, the nonuniformity of the specimen failure is enhanced, and the nonuniformity of the PFC simulation specimen is also enhanced. However, there are some differences between the simulated and the actual failure samples. The results show that the contact force chain is very weak at the precrack and macroshear plane, which indicates that the original contact force is weakened due to particle fracture. Therefore, with the increase of load, the bearing capacity of the specimen will decrease. The displacement at the shear plane of the PFC simulation sample is larger and is consistent with the experiment. Thereafter, the bulging effect of the sample is simulated. With the increase in the load, the fragments fall off and the fragments eject from the rock sample. This is due to the weakened contact force between the particles. Thereafter, fracture occurs with the formation of microcracks and the cracks converge. Thus, it provides a prerequisite for the transformation of elastic strain energy into kinetic energy, and, finally, the rock sample shows debris shedding and ejection.

\footnotetext{
4.4. Analysis of the Damage and the Energy Change for the Rock Sample. In order to reveal the damage and the failure mechanism of the rock with a single precrack and to understand the process of crack initiation and propagation, based on the fracture mechanism of particle bonding in PFC, the mesodamage variable $D$ is defined as $D=C_{\mathrm{d}} / C$, where $C$ is the total number of bonds between the particles and $C_{\mathrm{d}}$ is the number of broken bonds.
} 


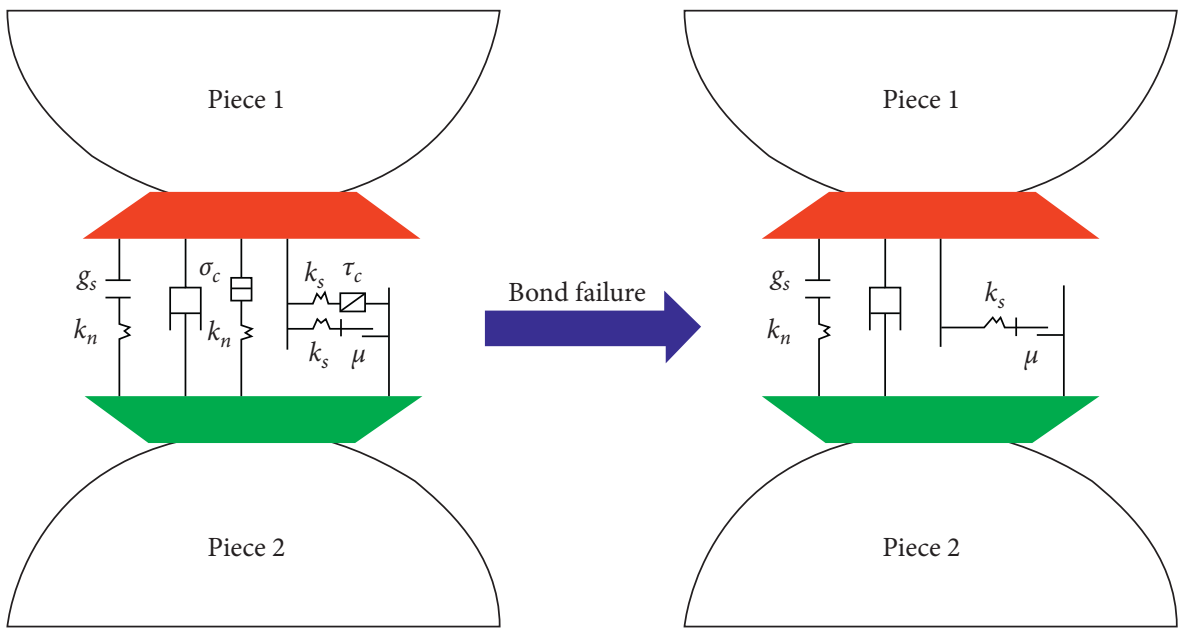

FIGURE 10: Schematic diagram of the parallel bonding model [35].

TABLE 3: Mesoparameters of the red sandstone for PFC2D simulation.

Parameters

Minimum radius of the particle $(\mathrm{mm})$

Particle size ratio

Particle density $\left(\mathrm{kg} \cdot \mathrm{m}^{-3}\right)$

Particle friction coefficient

Parallel bond modulus (GPa)

Parallel bond stiffness ratio

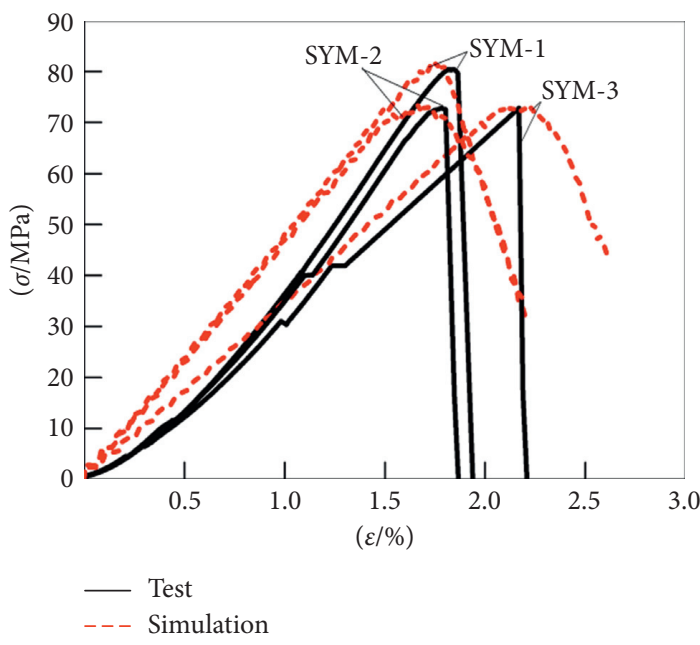

(a)
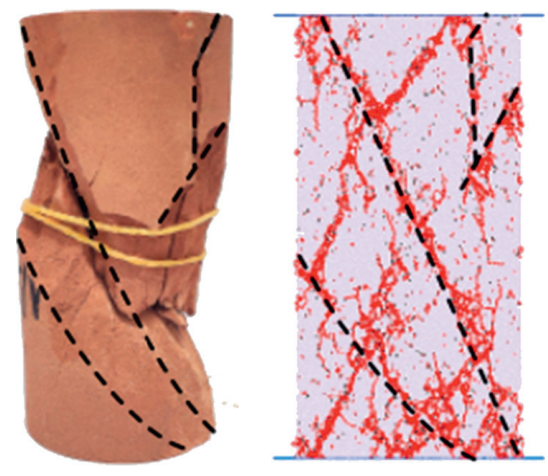

(b)

Figure 11: Comparison of experimental results and simulation results: (a) stress-strain curves and (b) shear planes after failure.

The energy can be traced and recorded in PFC. This includes the boundary energy (Eboundary), strain energy of the parallel bond (Epbstrain), particle sliding energy (Eslip), and the particle strain energy (Estrrain). The accumulated elastic strain energy of the rock sample is composed of the Epbstrain and the Estrain. In this paper, the elastic strain energy is defined as $W_{\mathrm{e}}=W_{\mathrm{pb}}+W_{\mathrm{s}}$, where $W_{\mathrm{pb}}$ is the strain energy of parallel bond and $W_{s}$ is the particle strain energy. The damage statistics of the simulated samples are shown in Table 4.

From Table 4, it is observed that there is a positive correlation between the number of microcracks and the mesodamage variable $D$. Therefore, the damage degree of the rock sample is described by $D$. It is also observed that, 


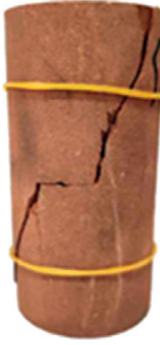

$\alpha=0^{\circ}$

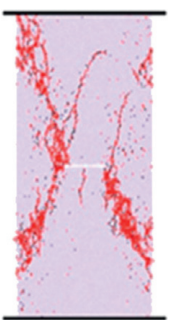

$\alpha=0^{\circ}$

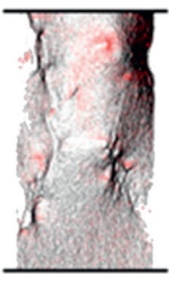

$\alpha=0^{\circ}$

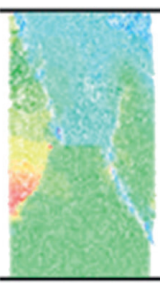

$\alpha=0^{\circ}$

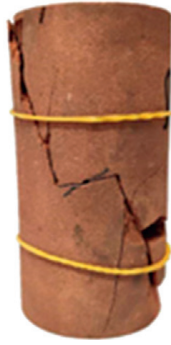

$\alpha=15^{\circ}$

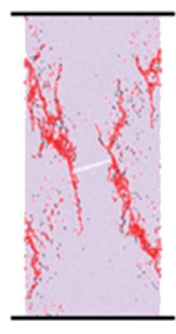

$\alpha=15^{\circ}$

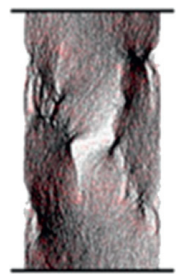

$\alpha=15^{\circ}$

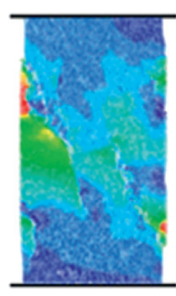

$\alpha=15^{\circ}$

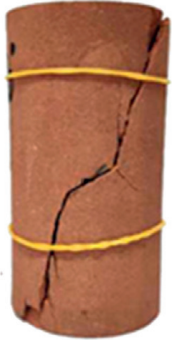

$\alpha=30^{\circ}$

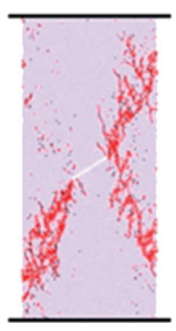

$\alpha=30^{\circ}$

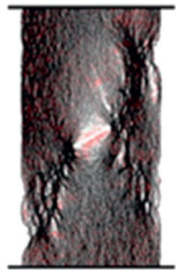

$\alpha=30^{\circ}$

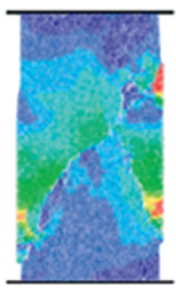

$\alpha=30^{\circ}$

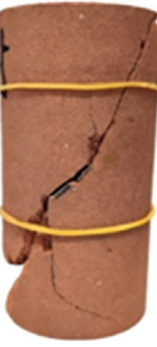

$\alpha=45^{\circ}$

(a)
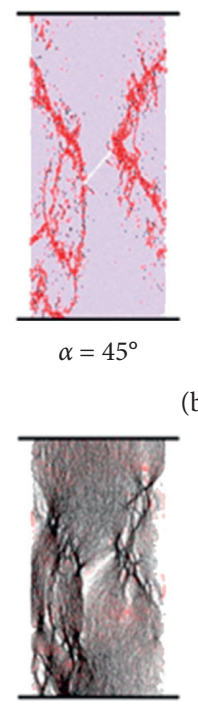

$\alpha=45^{\circ}$

(c)

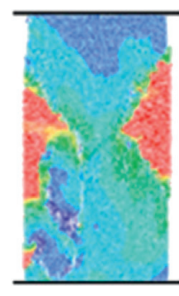

$\alpha=45^{\circ}$

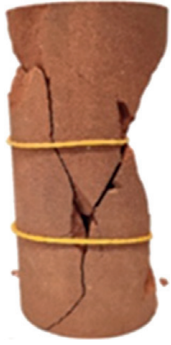

$\alpha=60^{\circ}$

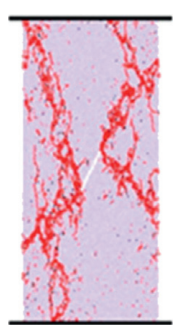

$\alpha=60^{\circ}$

(b)

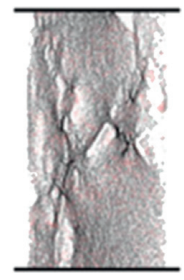

$\alpha=60^{\circ}$

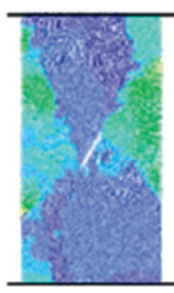

$\alpha=60^{\circ}$

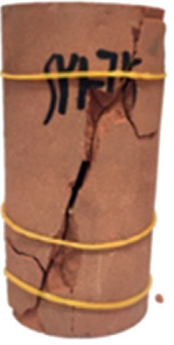

$\alpha=75^{\circ}$

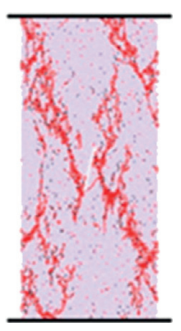

$\alpha=75^{\circ}$

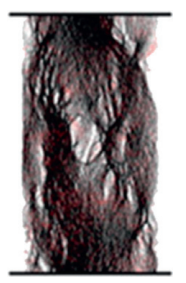

$\alpha=75^{\circ}$

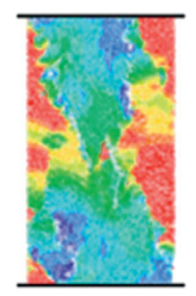

$\alpha=75^{\circ}$

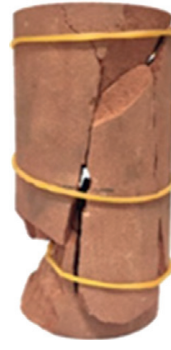

$\alpha=90^{\circ}$

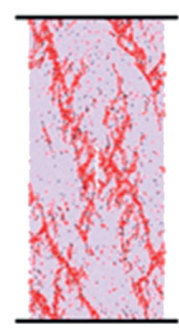

$\alpha=90^{\circ}$

Without fracture
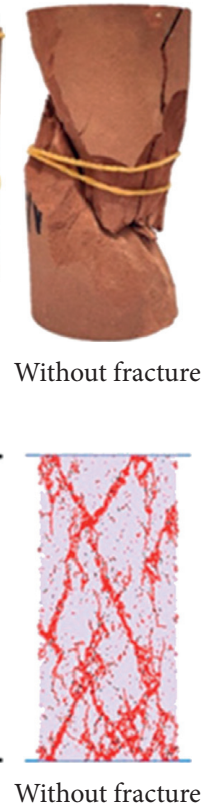

(d)

Figure 12: Numerical results of the red sandstone with a single precrack at different dip angles: (a) failure mode, (b) crack distribution, (c) contact force chain, and (d) displacement field.

as the crack dip angle increases, the peak strength, the number of microcracks, and the mesodamage variable increase. Thus, the damage degree of the rock increases accordingly.

The relationship between the stress, energy, and axial strain during loading is shown in Figure 13. From Figure 13, it is observed that the elastic strain energy reaches the maximum value on loading when the rock sample reaches the peak strength. Further, as the bearing capacity of the rock sample decreases, it is observed that the accumulated elastic strain energy is transformed into other forms of energy. At the same time, a certain number of microcracks occur in the region of the compressive stress concentration, and macrocracks are formed.

From the energy point of view, it is found that the elastic strain energy $W_{\mathrm{e}}$ is transformed into the sliding energy $W_{\text {slip }}$. Further, a part of the energy of $W_{\text {slip }}$ is used to drive the rock sample in order to produce microcracks, and the macrofragments fall off in the crack cross regions. Another part of the energy of $W_{\text {slip }}$ makes the rock sample unstable, which may drive the rock sample to eject. Finally, the microcracks coalesce in order to make the specimen fail. 
TABle 4: The damage statistics of the specimens with different crack dip angles.

Crack dip Peak strength (MPa) Peak strain Number of microcracks Total number of bonds Number of the angle $\left(^{\circ}\right)$ Peak strength $(\mathrm{MPa})$ Peak strain Number of microcracks Total number of bonds broken bonds

\begin{tabular}{|c|c|c|c|c|c|c|}
\hline \\
\hline 0 & 46.54 & 0.97 & 3300 & 56754 & 491 & 0.0087 \\
\hline 15 & 52.89 & 1.06 & 3379 & 56741 & 909 & 0.016 \\
\hline 30 & 52.63 & 1.08 & 3609 & 56750 & 994 & 0.018 \\
\hline 45 & 56.81 & 1.18 & 4865 & 56745 & 2033 & 0.036 \\
\hline 60 & 65.80 & 1.27 & 5589 & 57128 & 2920 & 0.051 \\
\hline 75 & 70.63 & 1.31 & 5985 & 56750 & 2842 & 0.050 \\
\hline 90 & 72.07 & 1.33 & 7352 & 56741 & 3780 & 0.067 \\
\hline Intact & 78.73 & 1.81 & 8822 & 56969 & 4937 & 0.087 \\
\hline
\end{tabular}
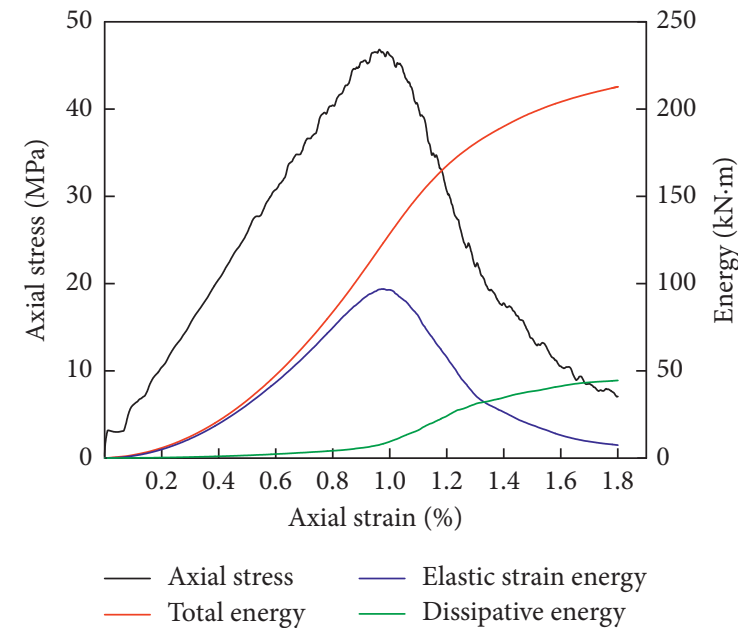

(a)
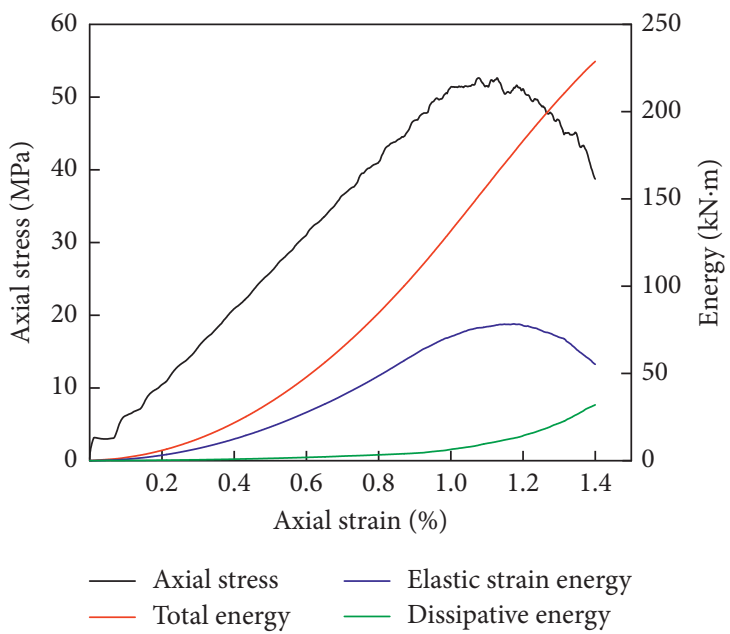

(c)

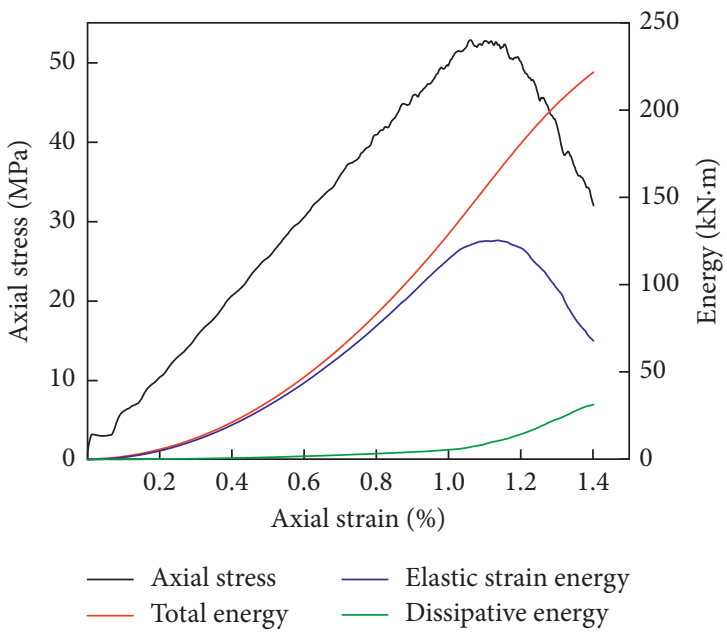

(b)
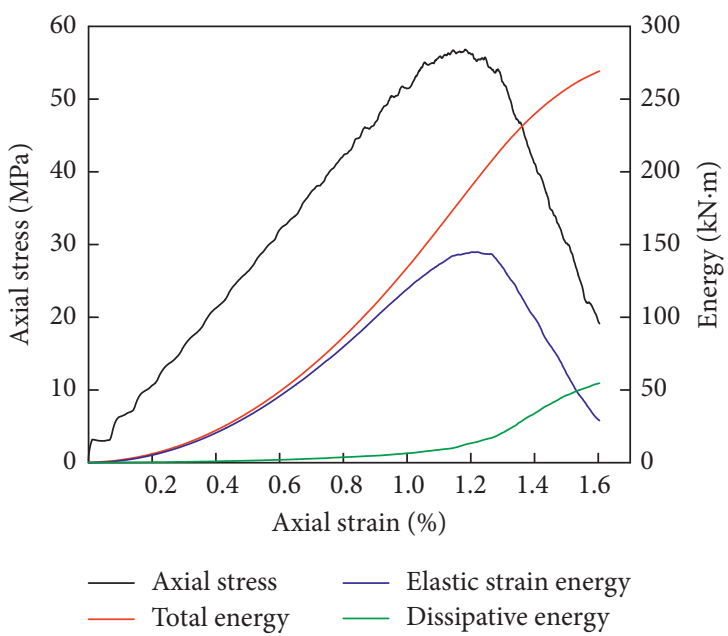

(d)

FIgURE 13: Continued. 

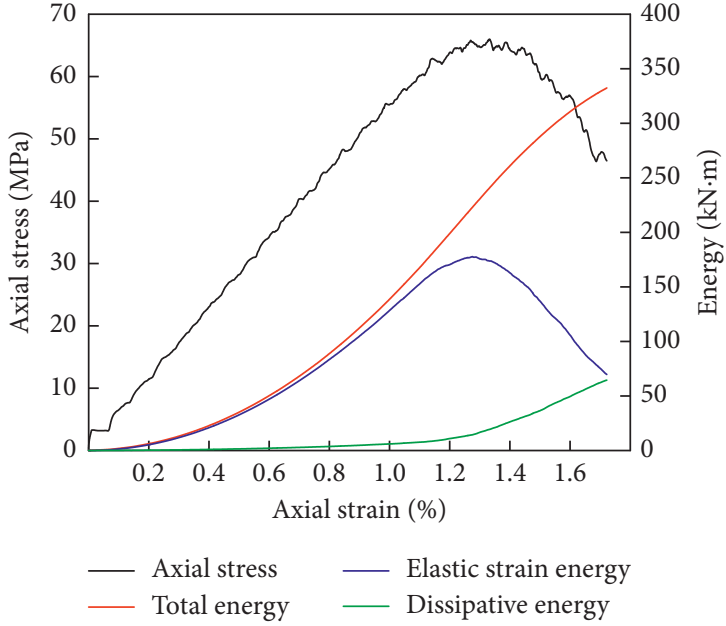

(e)
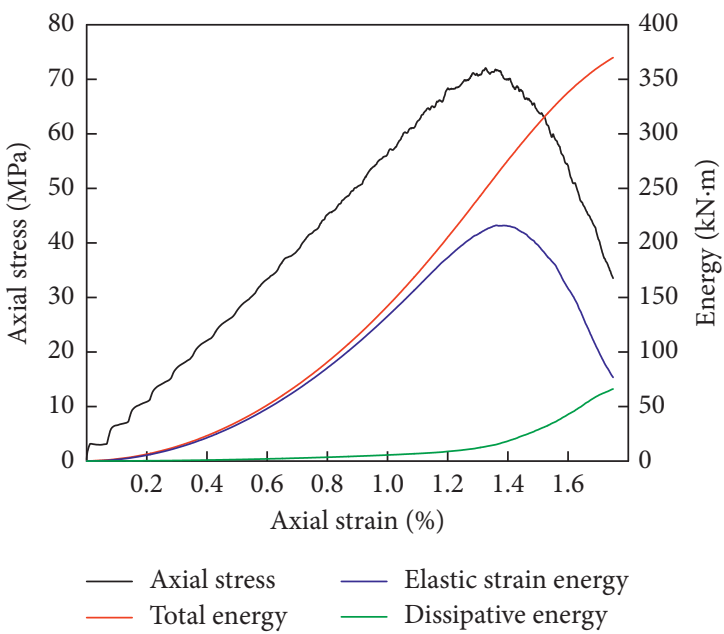

(g)

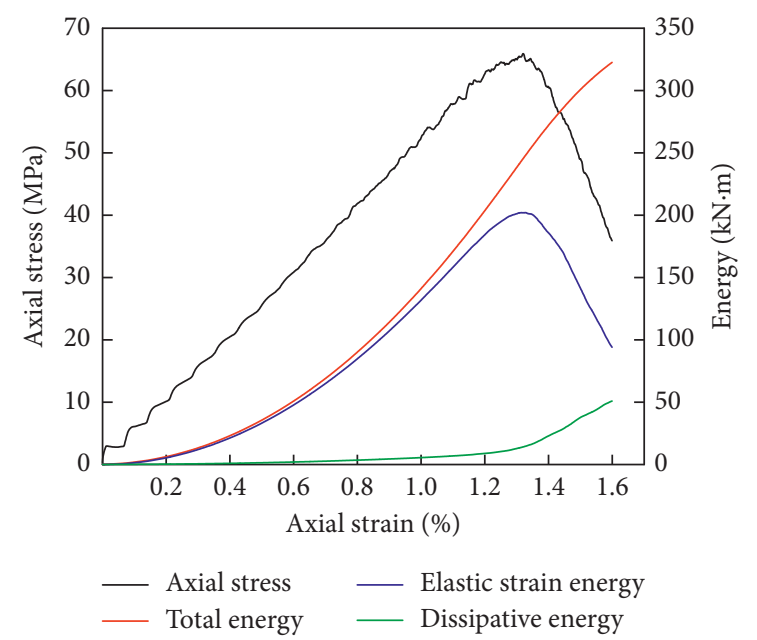

(f)

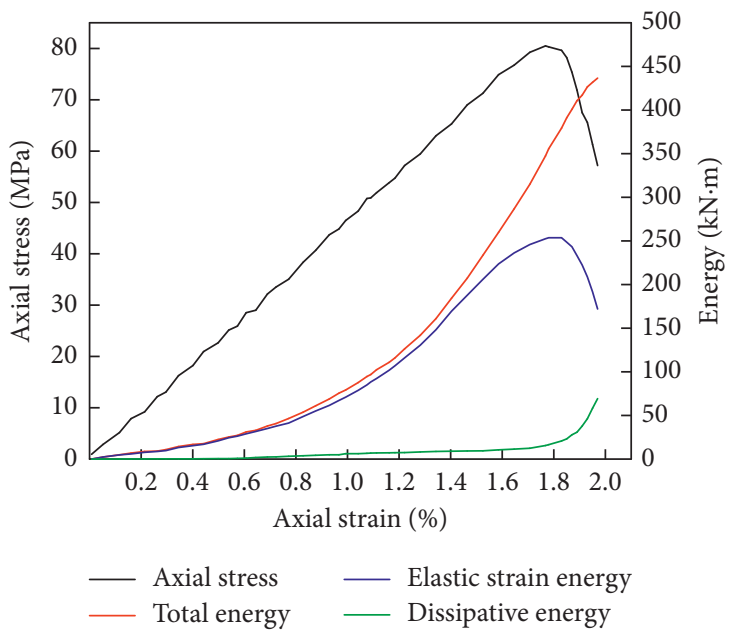

(h)

FiguRE 13: Relationship between the stress, energy, and the axial strain during loading at various crack dip angles: (a) $\alpha=0^{\circ}$, (b) $\alpha=15^{\circ}$, (c) $\alpha=30^{\circ}$, (d) $\alpha=45^{\circ}$, (e) $\alpha=60^{\circ}$, (f) $\alpha=75^{\circ}$, (g) $\alpha=90^{\circ}$, and (h) intact sample.

\section{Conclusions}

In this paper, studies are carried using the single precracked red sandstone. By conducting the uniaxial compression test and PFC2D simulation, the mechanical properties, crack propagation, failure mode, and the failure evolution characteristics of the single precracked red sandstone under different crack dip angles are studied. From the study, the following conclusions are obtained. The stress-strain curve of the precracked sandstone can be divided into five stages, namely, microfracture and pore compaction stage, elastic deformation stage, crack initiation and stable growth stage, crack acceleration and unstable fracture stage, and postpeak fracture instability stage.

Further, the peak strength, peak strain, and elastic modulus parameters of the precracked rock samples increase with the increase in crack dip angle, and the ultimate failure mode of the precracked rock samples transits from the "ladder" type failure to slope uneven failure.
PFC2D is used to study the crack propagation, force chain change, and displacement field of the single precracked red sandstone. The results show that tensile microcracks contribute more to the failure of rock samples than the shear cracks. Further, the contact force chain is very weak at the prefabricated cracks and the macroshear plane, which indicates that the original contact force is weakened due to particle fracture, so the bearing capacity of the specimen decreases with the increase in load.

In addition, from the results of the PFC simulation, it was observed that, as the uniaxial load increases, the contact force between the particles of the specimen weakens and the microcracks gradually propagate, resulting in the phenomenon of fragments falling off and the rock sample fragment ejection. Further, from the viewpoint of dynamics, the gradual convergence of the microcracks provides a prerequisite for the transformation of the elastic strain energy into kinetic energy. 


\section{Data Availability}

The data used to support the findings of this study are available within this article.

\section{Conflicts of Interest}

The authors declare that they have no conflicts of interest.

\section{Acknowledgments}

This work was supported by the Natural Science Foundation of Hunan Province, China (no. 2018JJ3166), and the Natural Science Foundation of China (nos. 51504091, 51774131, and $51774130)$.

\section{References}

[1] J. L. Fu, Y. Yuan, Y. L. Zhao et al., "Meso simulation of damage and failure characteristics of double fractured rock under uniaxial dynamic compression," Journal of Hunan University of Arts and Sciences, vol. 31, no. 3, pp. 57-63, 2019.

[2] Y. Zhu, "A micromechanics-based damage constitutive model of porous rocks," International Journal of Rock Mechanics and Mining Sciences, vol. 91, pp. 1-6, 2017.

[3] H.-L. Wang, W.-J. Chu, and M. He, "Anisotropic permeability evolution model of rock in the process of deformation and failure," Journal of Hydrodynamics, vol. 24, no. 1, pp. 25-31, 2012.

[4] T. Liu, P. Cao, and H. Lin, "Damage and fracture evolution of hydraulic fracturing in compression-shear rock cracks," Theoretical and Applied Fracture Mechanics, vol. 74, no. 1, pp. 55-63, 2014.

[5] X. P. Zhou and H. Q. Yang, "Dynamic damage localization in crack-weakened rock mass: strain energy density factor approach," Theoretical and Applied Fracture Mechanics, vol. 97, pp. 289-302, 2018.

[6] H. Y. Liu and T. M. Su, "A dynamic damage constitutive model for a rock mass with non-persistent joints under uniaxial compression," Mechanics Research Communications, vol. 77, pp. 12-20, 2016.

[7] D. Unteregger, B. Fuchs, and G. Hofstetter, "A damage plasticity model for different types of intact rock," International Journal of Rock Mechanics and Mining Sciences, vol. 80, pp. 402-411, 2015.

[8] C. Shi, W. K. Yang, J. X. Yang et al., "Calibration of microscaled mechanical parameters of granite based on a bondedparticle model with 2D particle flow code," Granular Matter, vol. 21, no. 2, pp. 1-13, 2019.

[9] R. H. Cao, P. Cao, H. Lin et al., "Failure characteristics of intermittent fissures under a compressive-shear test: experimental and numerical analyses," Theoretical \& Applied Fracture Mechanics, vol. 96, pp. 740-757, 2017.

[10] S.-Q. Yang, W.-L. Tian, Y.-H. Huang, P. G. Ranjith, and Y. Ju, "An experimental and numerical study on cracking behavior of brittle sandstone containing two non-coplanar fissures under uniaxial compression," Rock Mechanics and Rock Engineering, vol. 49, no. 4, pp. 1497-1515, 2016.

[11] B. X. Huang, X. Z. Cheng, B. W. Chen et al., "AE signals and space-time evolution characteristics in the failure process of red sandstone under uniaxial compression stress," Mining Research and Development, vol. 37, no. 5, pp. 24-29, 2017.
[12] Y. S. Chen, C. Pu, G. M. Li et al., "Experimental study on mechanical properties of rock mass samples with T-shaped cross crack subjected to uniaxial compression," Journal of Experimental Mechanics, vol. 34, no. 4, pp. 684-692, 2019.

[13] L. N. Y. Wong and H. H. Einstein, "Systematic evaluation of cracking behavior in specimens containing single flaws under uniaxial compression," International Journal of Rock Mechanics and Mining Sciences, vol. 46, no. 2, pp. 239-249, 2009.

[14] T. Jiang, X. Pan, J. Lei, J. Zhang, and W. Wang, "Rupture and crack propagation in artificial soft rock with preexisting fractures under uniaxial compression," Geotechnical and Geological Engineering, vol. 37, no. 3, pp. 1943-1956, 2019.

[15] D.-J. Wang, H. Tang, D. Elsworth, and C. Wang, "Fracture evolution in artificial bedded rocks containing a structural flaw under uniaxial compression," Engineering Geology, vol. 250, pp. 130-141, 2019.

[16] Y. Wang, J. Tang, Z. Dai, and T. Yi, "Experimental study on mechanical properties and failure modes of low-strength rock samples containing different fissures under uniaxial compression," Engineering Fracture Mechanics, vol. 197, pp. 1-20, 2018.

[17] S.-Q. Yang, Z. Yang, P.-C. Zhang, and W.-L. Tian, "Experiment and peridynamic simulation on cracking behavior of red sandstone containing a single non-straight fissure under uniaxial compression," Theoretical and Applied Fracture Mechanics, vol. 108, p. 102637, 2020.

[18] G. W. Ma, Q. Q. Dong, L. F. Fan, and J. W. Gao, "An investigation of non-straight fissures cracking under uniaxial compression," Engineering Fracture Mechanics, vol. 191, pp. 300-310, 2018.

[19] X. P. Zhang and L. N. Y. Wong, "Cracking processes in rocklike material containing a single flaw under uniaxial compression: a numerical study based on parallel bonded-particle model approach," Rock Mechanics and Rock Engineering, vol. 45, pp. 711-737, 2012.

[20] H. Lin, H. Yang, Y. Wang, Y. Zhao, and R. Cao, "Determination of the stress field and crack initiation angle of an open flaw tip under uniaxial compression," Theoretical and Applied Fracture Mechanics, vol. 104, p. 102358, 2019.

[21] Y. Niu, X.-P. Zhou, and F. Berto, "Evaluation of fracture mode classification in flawed red sandstone under uniaxial compression," Theoretical and Applied Fracture Mechanics, vol. 107, p. 102528, 2020.

[22] S. Li, D. Zhang, X. Bai et al., "Experimental study on mechanical properties, acoustic emission energies and failure modes of pre-cracked rock materials under uniaxial compression," Pure and Applied Geophysics, vol. 176, no. 10, pp. 4519-4532, 2019.

[23] C. Zhang, J. Niu, Q. Zhang, C. Zhao, and Y. Zhou, "Failure characteristics of rock-like materials with single flaws under uniaxial compression," Bulletin of Engineering Geology and the Environment, vol. 78, no. 1, pp. 593-603, 2019.

[24] S. Miao, P.-Z. Pan, Z. Wu, S. Li, and S. Zhao, "Fracture analysis of sandstone with a single filled flaw under uniaxial compression," Engineering Fracture Mechanics, vol. 204, pp. 319-343, 2018

[25] L. Liu, H. Li, X. Li, and R. Wu, "Full-field strain evolution and characteristic stress levels of rocks containing a single preexisting flaw under uniaxial compression," Bulletin of Engineering Geology and the Environment, vol. 79, no. 6, pp. 3145-3161, 2020.

[26] D. Li, E. Wang, X. Kong, M. Ali, and D. Wang, "Mechanical behaviors and acoustic emission fractal characteristics of coal specimens with a pre-existing flaw of various inclinations 
under uniaxial compression," International Journal of Rock Mechanics and Mining Sciences, vol. 116, pp. 38-51, 2019.

[27] Y. Lu, L. Wang, and D. Elsworth, "Uniaxial strength and failure in sandstone containing a pre-existing 3-D surface flaw," International Journal of Fracture, vol. 194, no. 1, pp. 59-79, 2015.

[28] Industrial standard compilation group of the People's Republic of China, SL264-2001, Rock Experiment Regulations for Water Conservancy and Hydropower Engineering, Water Conservancy and Hydropower Press, Beijing, China, 1981.

[29] R. L. Shan, Y. W. Song, H. Yang et al., "Experimental study on artificial frozen red sandstone characteristic stress under triaxial compression," Coal Engineering, vol. 50, no. 9, pp. 101-106, 2018.

[30] H. C. Xia and X. G. Zhu, "Research on the deformation characteristics and failure mode of sandstone under the condition of uniaxial compression test," Journal of Xi'an University of Technology, vol. 30, no. 3, pp. 309-314, 2014.

[31] Q. S. Liu, L. Wei, G. F. Lei et al., "Experimental study on damage strength of crack initiation and evaluation of brittle parameters of sandstone," Chinese Journal of Geotechnical Engineering, vol. 40, no. 10, pp. 1782-1789, 2018.

[32] C. Wu, F. Q. Gong, and Y. Luo, "A new quantitative method to identify the crack damage stress of rock using AE detection parameters," Bulletin of Engineering Geology and the Environment, 2020.

[33] F. Gong and C. Wu, "Identifying crack compaction and crack damage stress thresholds of rock using load-unload response ratio (LURR) theory," Rock Mechanics and Rock Engineering, vol. 53, no. 2, pp. 943-954, 2020.

[34] J. X. Tang, L. R. Kong, Y. L. Wang et al., "Experiment on effects of fissure dip angle and length on mechanical properties and failure modes of low-strength rock mass," Industrial Construction, vol. 49, no. 2, pp. 85-92, 2019.

[35] C. Shi, Q. Zhang, and S. N. Wang, "Numerical simulation technology and application of particle flow code (PFC5.0)," Rock and Soil Mechanics, vol. 39, no. S2, p. 43, 2018.

[36] A. Fakhimi and M. Lanari, "DEM-SPH simulation of rock blasting," Computers and Geotechnics, vol. 55, pp. 158-164, 2014.

[37] J. Gong and J. Liu, "Analysis on the mechanical behaviors of soil-rock mixtures using discrete element method," Procedia Engineering, vol. 102, pp. 1783-1792, 2015. 